\title{
Various Rotor Topologies of Line-Start Synchronous Motor for Efficiency Improvement
}

Research Article

\author{
Vasilija Jovan Sarac, Goce Stefanov \\ Faculty of Electrical Engineering, University Goce Delcev, Krste Misirkov 10-A, 2000 Stip, Republic of North Macedonia
}

Received April 09, 2020; Accepted August 25, 2020

\begin{abstract}
Line-start synchronous permanent magnet motor (LSSPMM) is being considered as a replacement or alternative to asynchronous squirrel-cage motor (AM) in constant speed applications. This is due to the better efficiency and power factor than the asynchronous motor. There are various rotor topologies of LSSPMM concerning the magnets placement and their dimensions. The paper analyses six different rotor topologies in terms of achieving the best efficiency and power factor for the same output power of the motor with minimal consumption of permanent magnet material. All other motor design parameters remain unchanged, i.e. all motor topologies are analysed for the same stator laminations and the same motor windings. The numerical finite element method (FEM) models and dynamic models for obtaining transient characteristics of speed, torque and current verify the proposed design of various motor models. The results from all motor models are compared and adequate conclusions are derived regarding the optimal rotor topology in terms of obtaining the best efficiency and power factor with minimal consumption of permanent magnet material, for the same output power of the motor.
\end{abstract}

Keywords: line-start synchronous permanent magnet motor • rotor topologies • transient characteristics • FEM

\section{Introduction}

Line-Start synchronous permanent magnet motor has gained popularity within recent years due to its features that combine easy line-start of the asynchronous motor and the high efficiency and power factor of the synchronous motor. The need for constructing and using more efficient electric motors is imposed by several regulations of the European Union (EU) that stipulate the usage of the high efficient electrical motors with IE4 efficiency class. The asynchronous motor encounters various design issues that prevent it to achieve an IE4 efficiency class. On the contrary, the line-start synchronous permanent magnet motor (LSSPMM) can reach the IE4 efficiency class because like all synchronous motors, it has a good power factor due to the permanent magnets in the rotor construction, which provide the magnetisation, i.e. no magnetisation current is needed like at AM (Binkowski, 2016). On the other hand, total losses are reduced due to nullified rotor losses at rated load operation, as there is no current in the rotor winding at the synchronous speed of operation. Therefore, the combination of the design of the asynchronous and synchronous motor in the rotor of LSSPMM (the squirrel cage winding from the asynchronous motor and the flux barriers with permanent magnets from the synchronous motor) has been proved a good combination in obtaining energy-efficient electric motors. Finding the optimal design of LSSPMM that combines the good starting characteristics with satisfactory steady-state operation has been a challenge for many researchers during the past decade. Some authors focused on the improvement of the rotor design by utilizing a novel rotor structure with two types of rotor slots or by using the deep bar effect (Xu, 2013; Zawilak, 2013; Zöhra et al., 2019). Others focus on the impact that various design parameters and materials, such as ferrites and different winding types, have on the motor performance (Sekerák et al., 2012). The mathematical and analytical models of LSSPMM that had been developed for normal and faulty operating conditions are important tools in understanding the motor operation (Stoia et al., 2009; Hussein et al., 2018). Improvement of starting capability, efficiency and

*Email: vasilija.sarac@ugd.edu.mk, goce.stefanov@ugd.edu.mk 
power factor of LSSPMM has been the subject of analysis of many types of research, and various motor design techniques have been applied to realise these targets. Some of them are pole changing method or improvement of the efficiency and power factor by adding magnets into flux barriers of the synchronous reluctance motor. The impact of the position and magnet length on the efficiency and power factor of the synchronous reluctance motor is analysed as well. (Tian et al., 2016; Kim at al., 2020). Optimisation techniques have gained popularity during recent years as they allow obtaining the most favourable solution of certain optimisation problem, within defined constraints, for the predefined target function. In the case of the LSSPMM, the multi-objective optimisation function is introduced that maximises the output power and efficiency (Ghoroghchian et al., 2019). Genetic algorithms, as one of the most popular stochastic optimisation methods, have been used in the optimisation of LSSPMM for the overall motor operation to be maximised (Ghahfarokhi et al., 2020). Besides, other optimisation algorithms have been applied in the optimisation of LSSPMM such as the bee colony algorithm or bat algorithm (Mutluer and Bilgin, 2016; Knypiński, 2017). Several other designs of permanent magnet-assisted synchronous reluctance motor and LSSPMM with super-premium efficiency are analysed that allow significant performance improvement and reduction of the amount of permanent magnet material (Bao et al., 2011; Ashkezari et al., 2017; Gwoździewicz and Zawilak, 2016). Some specific applications of the synchronous permanent magnet motors in tower cranes for automotive electromechanical braking system and at high-speed machines have been described (Trifa et al., 2012; Gieras, 2020; Knypiński and Krupinski, 2020). The optimal rotor topology has been the subject of the research by implementing the genetic algorithms in finding the optimal rotor dimension regarding flux barriers and permanent magnets (Dinh, 2017). The latter research is focused on one specific rotor topology and its improvement by the aid of genetic algorithms. Other authors who implemented optimisation techniques in finding the best rotor design in terms of minimal magnet consumption and the best performance characteristics have analysed various rotor topologies of the LSSPMM concerning the efficiency also (Els et al., 2014). In the mentioned research various motor models have been presented but not for the same output power of the motors. The object of the research of this paper is to find the best rotor design that allows to obtain the good starting characteristics, high efficiency and power factor at rated load operation while maintaining the same output power of the motor. Therefore, six different rotor topologies are analysed for obtaining the best efficiency and power factor with the smallest consumption of the permanent magnet material for the same power output of the motor. In all models, the position and the shape of the flux barriers are different and the length of the air gap is changed compared with the asynchronous motor. The other motor parameters remain the same, i.e. the stator laminations, outer dimensions of the motor and both windings in all six models of the line-start synchronous motor. For all six versions of the rotor, computer models have been defined, that are solving analytical models of the motor for obtaining the steady-state operating characteristics and parameters. After parameters and characteristics of all motor models at various operating regimes are obtained, adequate conclusions are derived for the most favourable solutions (rotor configurations) regarding efficiency, power factor and consumption of the permanent magnet material. For the most favourable solutions, the steady-state operating characteristics are plotted. Besides, also the numerical models of the motors are derived by the aid of the Finite Element Method (FEM) that allows the flux density in the cross-section of the motors to be calculated and presented. Finally, the transient characteristics of the motors are calculated at motor acceleration at no load and with step load applied to the motor shaft. The dynamic behaviour of all motor models is analysed and the obtained results are compared with analytical models. The presented analysis should help motor designers to choose the most favourable rotor topology, among numerous known rotor topologies, for this type of the motor that provides the best motor performance along with the minimal consumption of permanent magnet material.

\section{Analysis of steady state-operation of motor models}

The starting point in the analysis is the asynchronous squirrel-cage motor type 2AZ155-4 or the new model of the motor-5AZ100LA-4, a product of company Rade Končar from Croatia. Firstly, the asynchronous motor was modelled in the software Ansys Electronics Desktop, i.e. in the module of the software RMxprt that allows calculating motor parameters and steady-state operating characteristics. We will refer to this model of the asynchronous motor as AM. The rotor of the asynchronous motor was redesigned by adding flux barriers and permanent magnets to obtain a line-starting synchronous permanent magnet motor. This first model of the synchronous motor and its rotor configuration will be referred to as the basic model (BM). Later on, five different variants of the rotor will be designed 

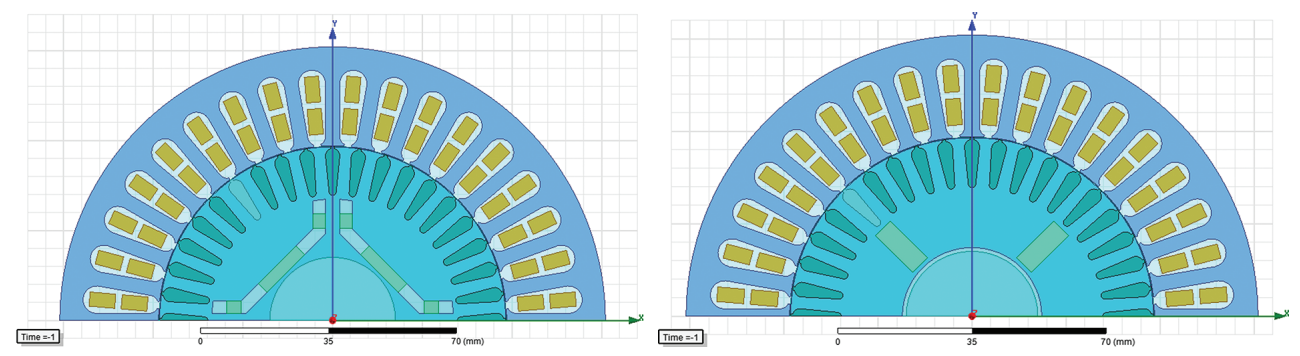

(a) BM (b) V1
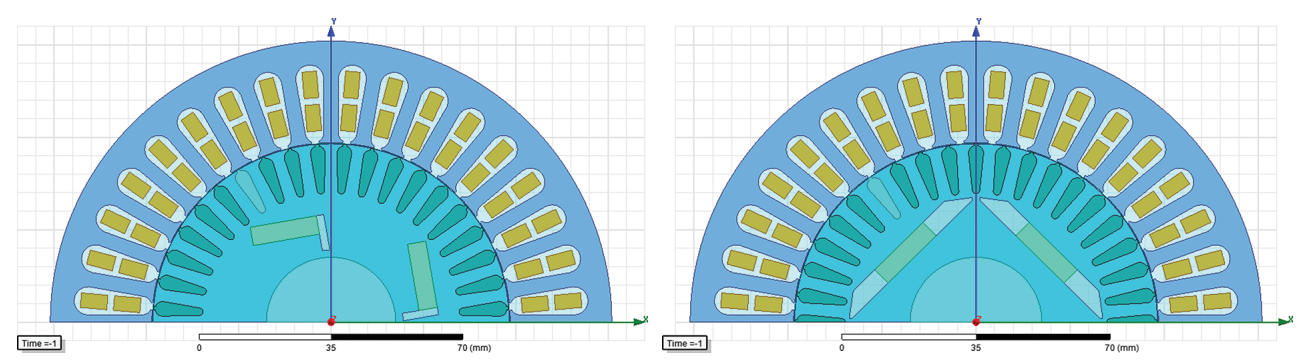

(c) V2 (d) V3
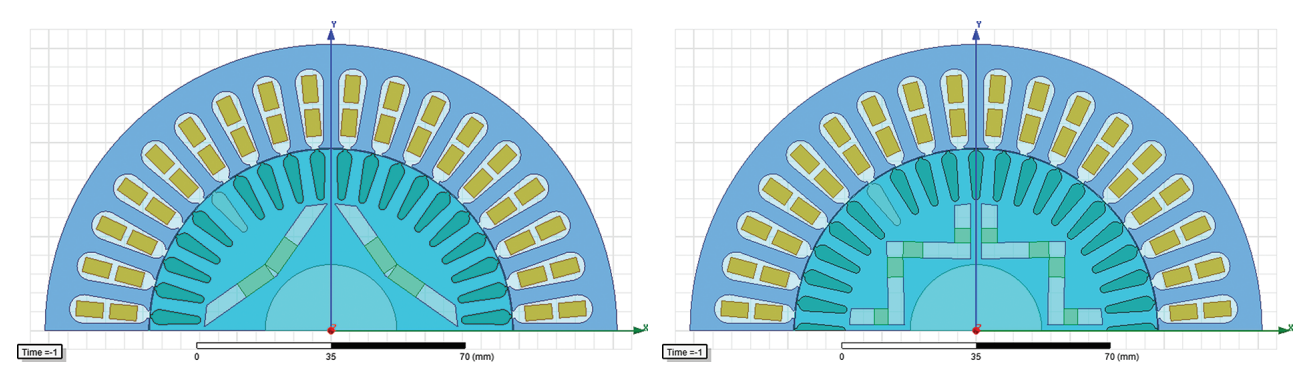

(e) V4 (f) V5

Fig. 1. Cross-section of various motor designs

and they will be referred in the text as variant $1,2, \ldots(\mathrm{V} 1$ to $\mathrm{V} 5)$. The design of $\mathrm{BM}$ and $\mathrm{V} 1$ to $\mathrm{V} 5$ is presented in Figure 1. In all motor models, the stator lamination remains unchanged as well as the stator winding and the squirrel cage winding of the rotor. The asynchronous motor was chosen as a reference with which obtained results of parameters and characteristics of the synchronous motors are compared. This is due to the available data for the asynchronous motor from the producer as well as from the measurements in the faculty laboratory. The producer data can be found in the catalogue of company Končar and they are used as a reference in comparison of obtained data of newly derived models of the motors (Končar-MES d.d., 2014). The measurements of the asynchronous motor in the faculty laboratory were based on standard no-load, locked rotor tests and measurements of the loaded asynchronous machine (Sarac et al., 2017). As these test procedures are standardised, they are presented here only with the obtained results from them in Table 1. Software Ansys RMexprt was used for modelling analytical models of the motors for calculating motor parameters and characteristics. Therefore, the motor cross-section with exact dimensions, obtained from the motor producer, was inputted in the software together with properties of all materials that were used in the motor construction. After models of the AM and BM were solved, as an output, motor parameters and characteristics were obtained for no-load, rated load and locked rotor. They are presented in Table 1.

The similarity of the results of AM, measurement and producer's data ensures that the computer model of AM for calculating motor parameters and steady-state characteristics are accurate enough. Therefore, this model can be redesigned in the line-start synchronous motor (BM) and again solved for obtaining main motor parameters. The results of the BM are also presented in Table 1. The synchronous motor was designed to have the same output 
Table 1. Comparison of AM, BM, measurements and producer's data

\begin{tabular}{lcccc}
\hline Parameter & AM & Measurements & Producer & BM \\
\hline \hline Phase current $\mathrm{I}_{1}(\mathrm{~A})$ & 5.2 & 4.9 & 4.9 & 3.7 \\
No-load current $\mathrm{I}_{\mathrm{o}}(\mathrm{A})$ & 2.9 & 2.4 & 2.4 & 2.9 \\
No-load power $\mathrm{P}_{\mathrm{o}}(\mathrm{W})$ & 135 & 196 & 170 & 89 \\
Locked-rotor current $\mathrm{I}_{\mathrm{k}}(\mathrm{A})$ & 22 & 22 & 25 & $/$ \\
Locked rotor torque ratio $\mathrm{T}_{\text {star }} \mathrm{T}_{\mathrm{n}}(\mathrm{)}$ & 2.3 & $/$ & 2.2 & 4.3 \\
Breakdown torque ratio $\mathrm{T}_{\max } / \mathrm{T}_{\mathrm{n}}()$ & 2.4 & $/$ & 2.3 & 2.9 \\
Output power $\mathrm{P}_{2}(\mathrm{~kW})$ & 2.2 & 1.9 & 2.2 & 2.2 \\
Power factor $\cos \varphi()$ & 0.80 & 0.78 & 0.81 & 0.96 \\
Rated speed $\mathrm{n}_{\mathrm{n}}(\mathrm{rpm})$ & 1356 & 1410 & 1410 & 15 \\
Rated torque $\mathrm{T}_{\mathrm{n}}(\mathrm{Nm})$ & 15.5 & 13 & 81 & 1500 \\
Efficiency $(\%)$ & 79.4 & 77.5 & 94.9 \\
\hline
\end{tabular}

Table 2. Comparison of all six versions of LSSPMM

\begin{tabular}{|c|c|c|c|c|c|c|}
\hline Parameter & BM & V1 & V2 & V3 & V4 & V5 \\
\hline No-load current $I_{0}(A)$ & 2.9 & 3 & 3.2 & 2.6 & 2.6 & 2.6 \\
\hline Phase current $\mathrm{I}_{1}(\mathrm{~A})$ & 3.7 & 3.8 & 4 & 3.6 & 3.6 & 3.6 \\
\hline Total losses $\mathrm{P}_{\text {total }}(\mathrm{W})$ & 118 & 116 & 130 & 111 & 114 & 115 \\
\hline Input power $P_{1}(W)$ & 2317 & 2315 & 2330 & 2310 & 2314 & 2314 \\
\hline Output power $\mathrm{P}_{2}(\mathrm{~W})$ & 2199 & 2199 & 2199 & 2198 & 2200 & 2200 \\
\hline Power factor $\cos \varphi(/)$ & 0.96 & 0.94 & 0.88 & 0.98 & 0.97 & 0.97 \\
\hline Efficiency $\eta(\%)$ & 94.9 & 94.9 & 94.3 & 95.2 & 95.1 & 95 \\
\hline Permanent magnet material $(\mathrm{kg})$ & 0.59 & 0.74 & 0.52 & 0.50 & 0.51 & 0.53 \\
\hline Rated speed $n_{n}(r p m)$ & 1500 & 1500 & 1500 & 1500 & 1500 & 1500 \\
\hline Rated torque $T_{n}(\mathrm{Nm})$ & 14 & 14 & 14 & 14 & 14 & 14 \\
\hline Maximum output power $\mathrm{P}_{\max }(\mathrm{W})$ & 6473 & 7588 & 4899 & 7635 & 6640 & 6537 \\
\hline Torque angle $\left({ }^{\circ}\right)$ & 61.3 & 65.5 & 68.5 & 62.1 & 63.7 & 63.3 \\
\hline Starting torque $T_{\text {start }}(\mathrm{Nm})$ & 60.8 & 59.2 & 61.7 & 59.5 & 60.4 & 60.5 \\
\hline
\end{tabular}

power as the asynchronous motor. Like in all synchronous motors with permanent magnets the magnetisation of the motor is provided by permanent magnets, so no magnetisation current is needed like in the asynchronous motors. Consequently, the line current is decreased. The power factor of the synchronous motor is increased compared with the asynchronous motor, also the efficiency. It is expected, the line-start synchronous motor to have increased efficiency concerning the asynchronous motor due to reduced total losses i.e. reduced losses in the rotor winding. As the BM operates with synchronous speed, which is slightly bigger than the rated speed of the AM, for the same output power, the rated torque is slightly reduced. The output power of the synchronous motor remains unchanged compared with the model of the asynchronous motor. From the presented results in Table 1, it can be concluded that the starting model of the synchronous motor (BM) is sufficiently accurate and it can be redesigned in five more variants of the line-start synchronous motor. The main purpose of these various designs of the synchronous motor is to determine which design allows in obtaining the best efficiency and power factor with minimum consumption of permanent magnet material for the same output power of the motor. The various designs of the synchronous motor are presented in Figure 1. The obtained parameters and characteristics of all six models are presented in Table 2. The total losses, presented in Table 2, include friction and windage losses, which are calculated as $1 \%$ of the motor output power (Kumar and Manamalli, 2013).

The models V3, V4 and V5 show promising results regarding the efficiency, power factor, consumption of permanent magnet material and overload capability. The features of the model $\mathrm{V} 3$ can be considered as the best 

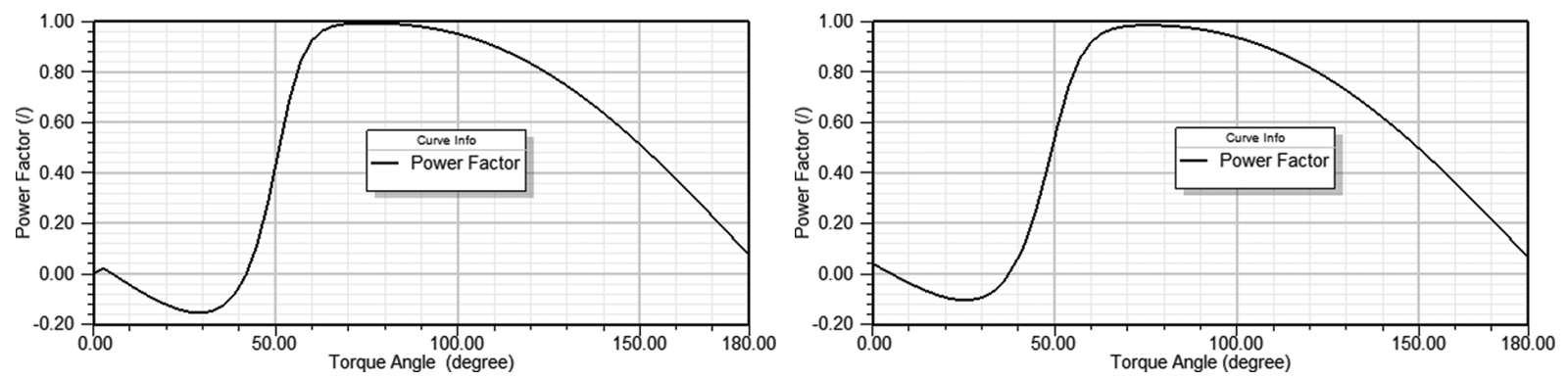

(a) V3 (b) V4

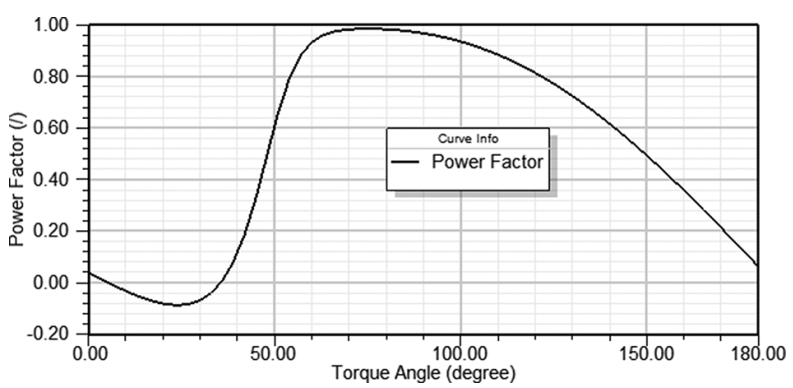

(c) V5

Fig. 2. Steady-state characteristics of power factor

from all models regarding the efficiency, power factor, the consumption of the permanent magnet material as well as the static overload factor (3.47). Models V3, V4 and V5 will be further analysed concerning the steady-state characteristics, and their numerical and dynamic modelling. Figure 2 presents the steady-state characteristics of the power factor for the models V3, V4 and V5 and supports the data presented in Table 2. For the specific torque angle, the power factor can be read from the presented characteristics in Figure 2.

The characteristics of efficiency are presented in Figure 3 for the analysed models. Again for the adequate torque angle, the efficiency of the model can be read.

The output mechanical torque of all motors is the same as all models have the same output power (constraint with which all the models were derived) and the same synchronous speed of operation. Typically, for line-start synchronous motors with permanent magnets, two types of torque contribute to the motor operation: asynchronous torque at motor starting, produced by squirrel cage winding, and torque produced by permanent magnets which acts as a breaking torque during motor starting and enables motor synchronisation in steady-state operation. The resulting torque in LSSPMM is the sum of these two types of torque, described above. The torque of the original asynchronous motor is presented in Figure 4. Figure 4 supports the data of the torque of the asynchronous motor in Table 2, i.e. $M_{\text {start }}=2.3 \times M_{n}, M_{\max }=2.4 \times M_{n}$. Similar data can be found in the catalogue of company Končar (KončarMES d.d., 2014). The break down slip for the asynchronous motor is 0.62 . Figure 5 presents the starting torque of $\mathrm{V} 4$, plotted versus normalised speed.

\section{Numerical (FEM) models}

The design of the motors is verified for magnetic flux density distribution in the cross-section of the machine by the aid of FEM. The cross-section of the machine is divided into numerous elements in which the magnetic vector potential $\mathbf{A}$ is solved and consequently the flux density $\mathbf{B}$ is calculated as well. With the aid of $\mathbf{B}$, the points with a high saturation of the core can be detected, and consequently, the machine design can be improved. The distribution of the flux density for the chosen models is presented in Figure 6. 

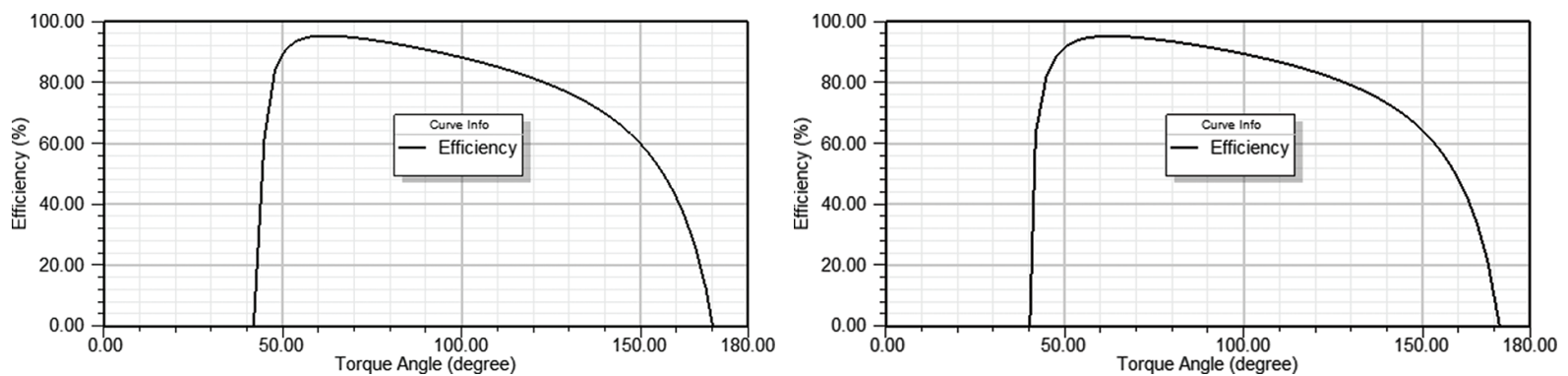

(a) V3 (b) V4

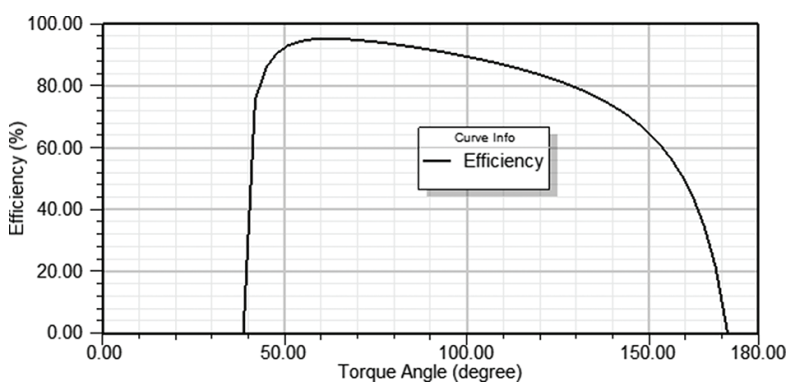

(c) V5

Fig. 3. Steady-state characteristics of efficiency

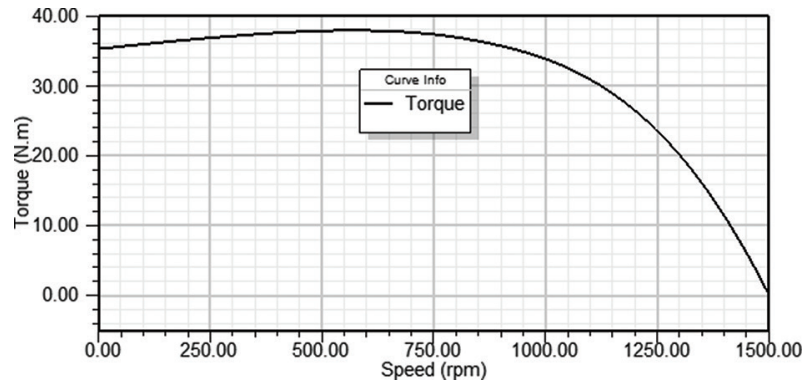

Fig. 4. The torque of the asynchronous motor

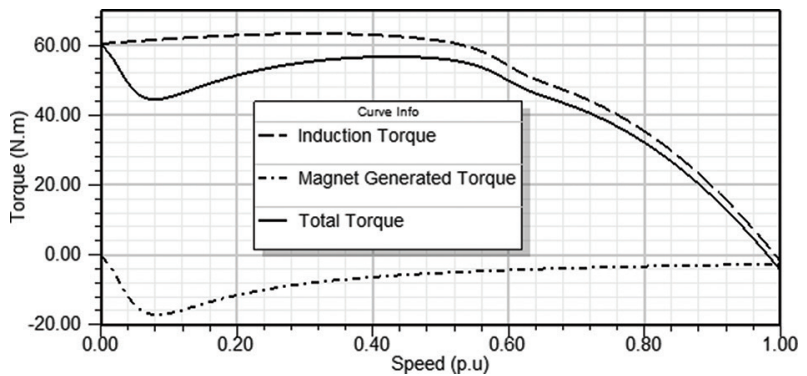

Fig. 5. Starting torque of $\mathrm{V} 4$ 

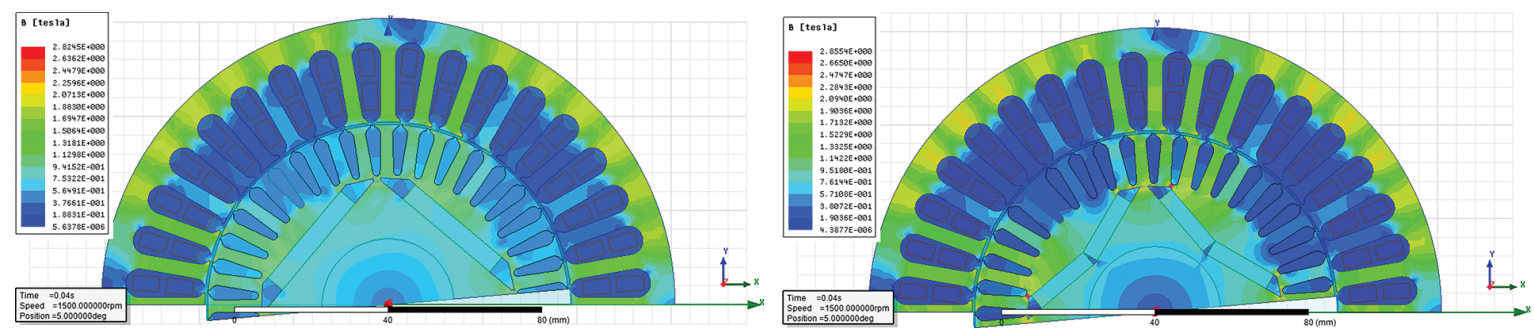

(a) V3 (b) V4

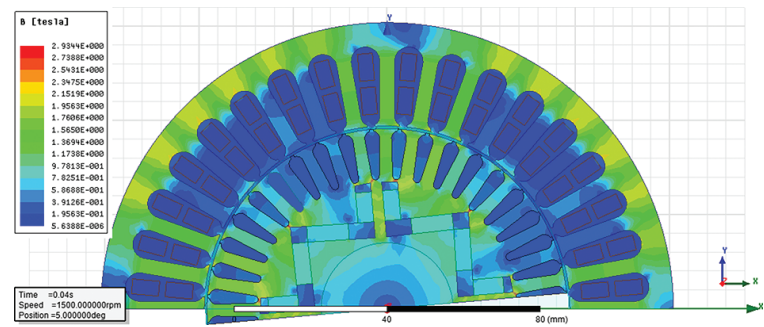

(c) V5

Fig. 6. Flux density distribution

\section{Dynamic models and transient characteristics}

Line starting of the synchronous motors with permanent magnets is one of the most important features that make them a suitable candidate for the replacement of asynchronous squirrel cage motors in constant speed applications. They have better efficiency and power factor than the asynchronous motors and design that can reach the IE4 efficiency class. However, LSSPMM cannot be used in all applications, especially with high load inertia like fans that can limit synchronisation capability of the machine. The proper dimensioning of rotor bars and the dimensions and quantity of permanent magnet material is of key importance for this type of motors. It can be stated that the increase of the permanent magnet flux worsens the synchronisation capabilities of the machine. On the other hand, the increase of permanent magnet material increases the efficiency and power factor in the steady-state operation. The induction torque can be maximised near the synchronous speed to maximise the synchronisation capability of the motor by lowering the cage resistance. On the other hand, the reduction of cage resistance reduces the starting torque of the motor. The modelled line-start synchronous motor has the same squirrel-cage winding of the asynchronous motor. The motor is well designed regarding the squirrel cage winding and the permanent magnet material as it has a sufficiently large starting torque. (Table 2 and Figure 4). All motor models are modelled for the same stator laminations. The stator winding, also the squirrel cage winding, is the same in all motor models. The only difference in the design is the position and shape of flux barriers, air gap length as well as required quantity of the permanent magnet material to reach the same output power for all motor models. The estimation of motor dynamic behaviour can be based on transient characteristics of speed, current and torque when the motor accelerates from a stand still up to the synchronous speed. Two different cases are simulated in the dynamic models: acceleration with step load, equal to the rated load, loaded to the motor shaft $300 \mathrm{~ms}$ after motor starting and acceleration with the rated load. Figure 7 presents the transient characteristics of speed when motors are loaded with the step load. Figure 8 presents the same characteristics for acceleration with rated load.

Figure 9 presents the torque characteristics of all three models when a step load equal to the rated load is applied to the motor shaft. Figure 10 presents the torque of all three models for acceleration with the rated load.

Figure 11 presents the line current characteristics of all three models when a step load equal to the rated load, is applied to the motor shaft. Figure 12 presents the line current of all three models for acceleration with the rated load. 

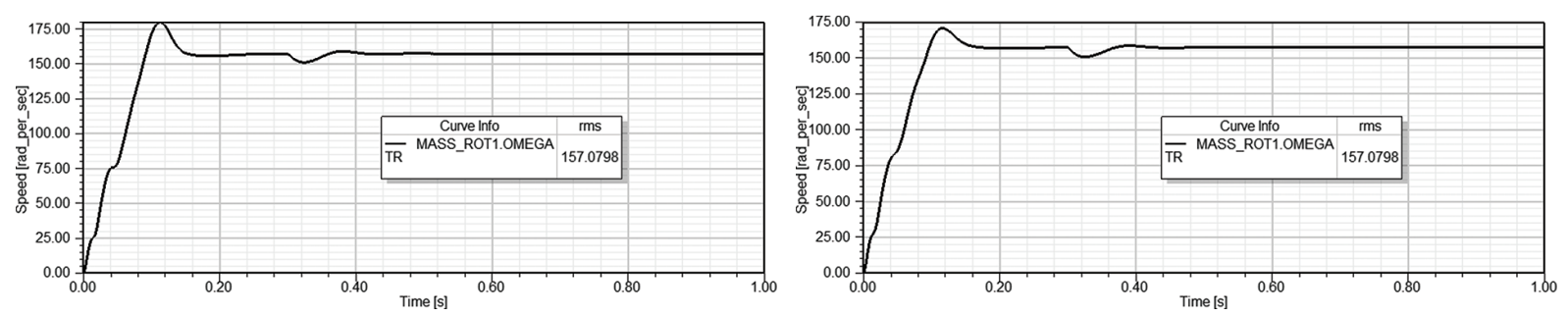

(a) V3 (b) V4

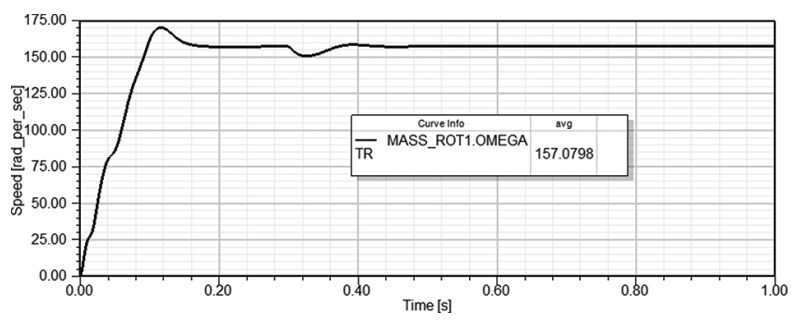

(c) V5

Fig. 7. Transient characteristics of speed at step load
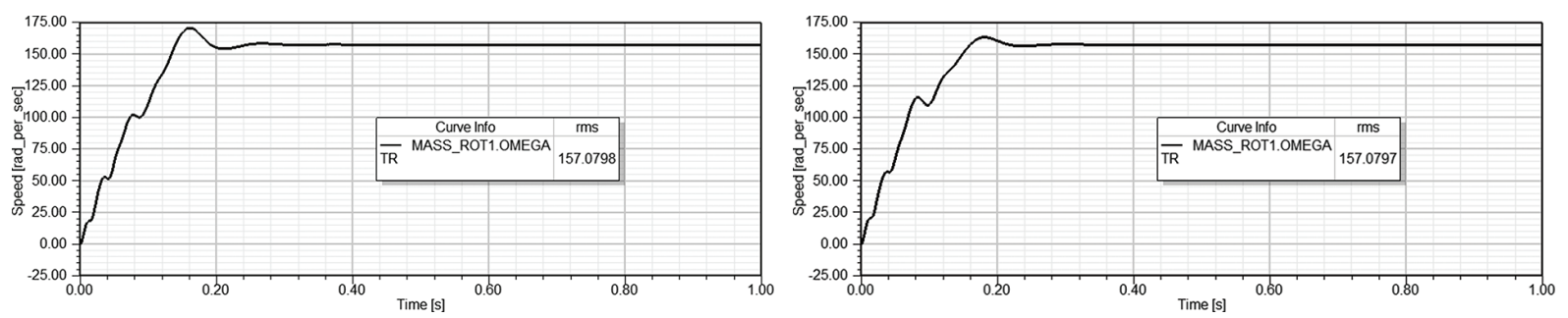

(a) V3 (b) V4

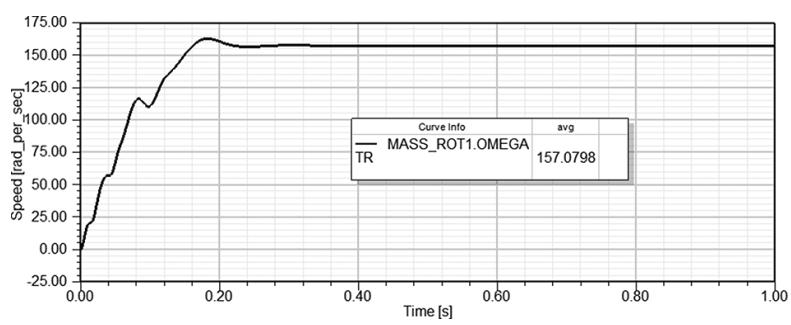

(c) V5

Fig. 8. Transient characteristics of speed at rated load

\section{Discussion of the results}

The motor designers are facing challenges in their everyday work to find the most optimal motor configuration in terms of material consumption and the price of the motor combined with optimal operating characteristics i.e. high efficiency and power factor, good starting torque and stable operation in transient regimes and at sudden load changes. These tasks can be even more challenging in the case of the line-start synchronous permanent magnet motor where there are numerous options for the rotor design, i.e. positions and dimensions of the flux barriers 

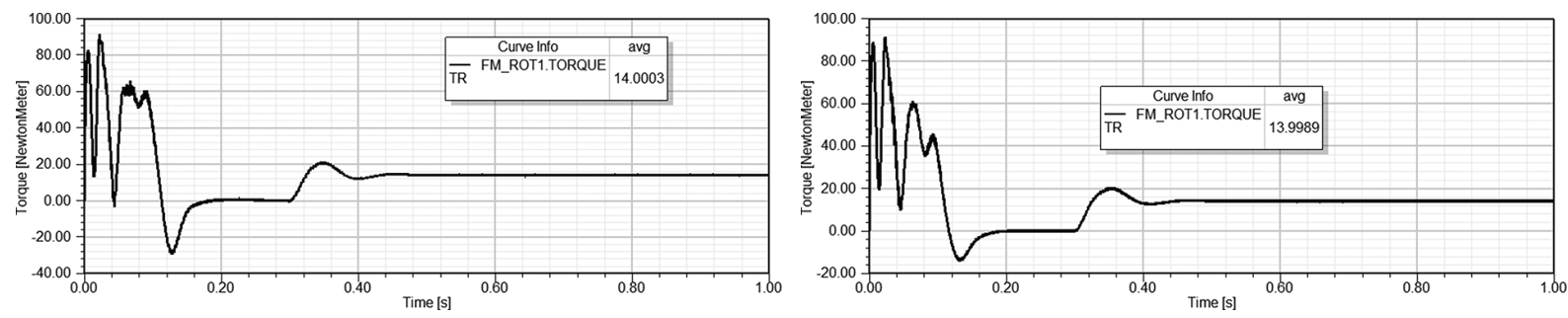

(a) V3 (b) V4

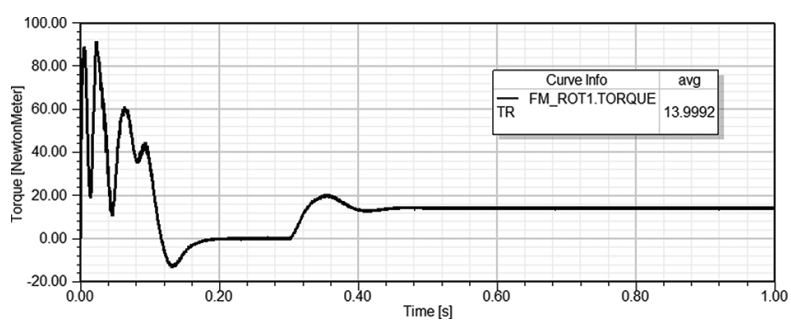

(c) V5

Fig. 9. Transient characteristics of torque at step load
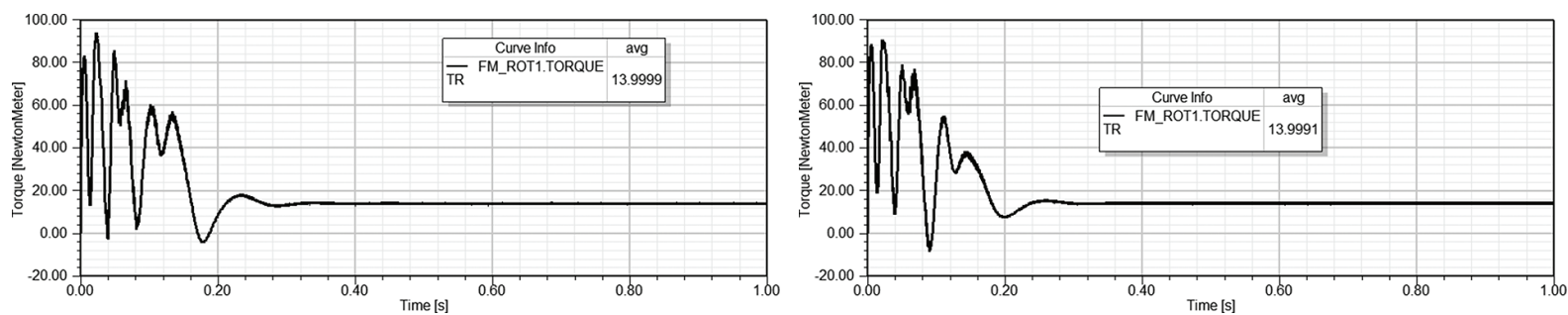

(a) V3 (b) V4

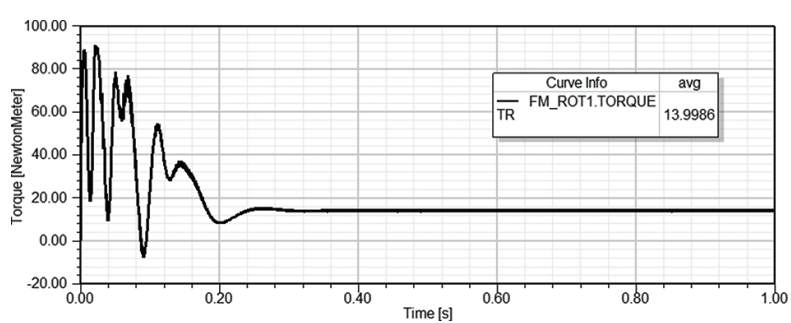

(c) V5

Fig. 10. Transient characteristics of torque at rated load

and magnets. Six different models of LSSPMM are analysed, presented in Figure 1, concerning three factors: efficiency, power factor and the consumption of permanent magnet material. In all motor models, three constraints are preserved: output power in all models should remain unchanged, the motor outer dimensions should remain the same, also motor windings should remain unchanged. The variations in all motor models are dimensions of the flux barriers, their position and the dimensions of the permanent magnets, necessary, to achieve the desired output power of the motor and the length of the air gap. By redesigning the rotor of the analytical model of asynchronous motor AM, by adding flux barrier and permanent magnets, the first model of LSSPMM is obtained, model-BM (Figure 1a). The analytical model of the asynchronous motor (AM) is calculated and designed on the base of exact 

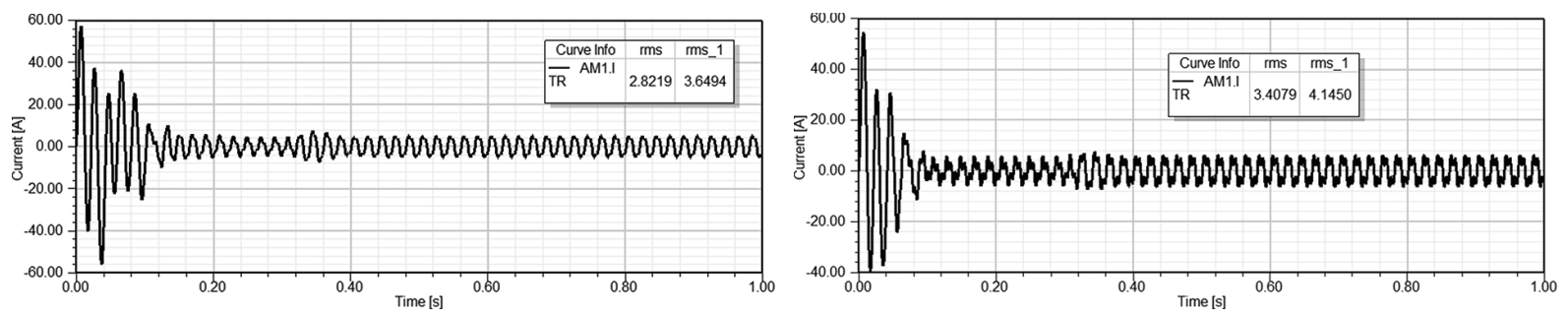

(a) V3 (b) V4

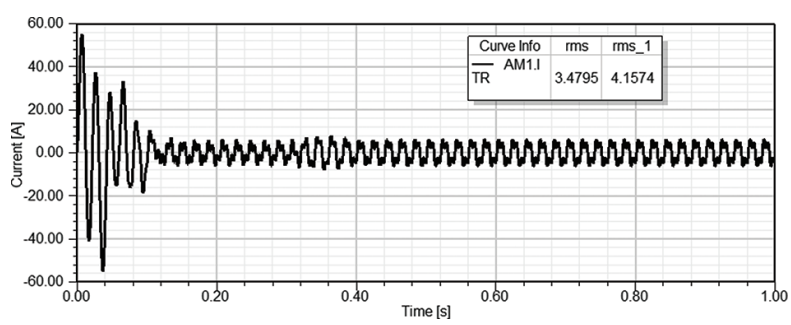

(c) V5

Fig. 11. Transient characteristics of current at step load
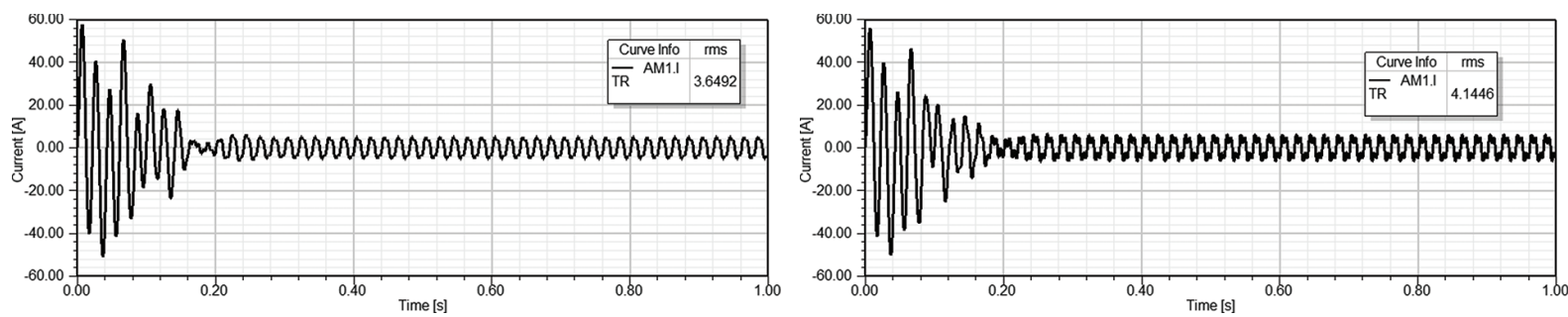

(a) V3 (b) V4

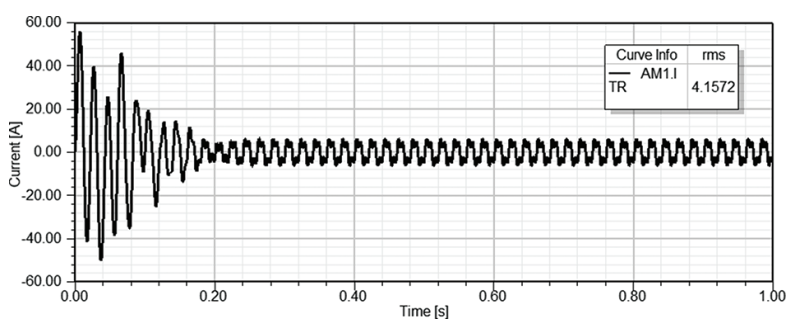

(c) V5

Fig. 12. Transient characteristics of current at rated load

core laminations and motor dimensions from the company Končar. From the comparison in Table 1, it can be concluded that BM has the same power output as AM-2.2 kW with decreased line current i.e. 3.7 A in comparison with $5 \mathrm{~A}$ of $\mathrm{AM}$. This can be expected as magnets provide the magnetisation of the synchronous motor, i.e. no magnetisation current is drawn from the network and consequently motor current is decreased. Synchronous motors operate with higher efficiency and power factor than the asynchronous motors and this is the case with the BM model. The BM operates with the synchronous speed, slightly bigger than the rated speed of the asynchronous motor, and therefore for the same output power, the output torque of BM is slightly smaller, i.e. $14 \mathrm{Nm}$ versus $15.5 \mathrm{Nm}$ of $\mathrm{AM}$. The starting torque of $\mathrm{BM}$ is 4.34 times bigger than the rated torque, which provides good starting 
capabilities of the designed BM model. The overload capabilities of BM can be considered satisfactory, as the maximum developed power is $6473 \mathrm{~W}$ that provides the maximum torque of $41.2 \mathrm{Nm}$ or 2.9 times bigger than the rated torque.

Once that was verified that BM is accurately modelled, five more variants of LSSPMM were derived with different rotor configurations. Table 2 presents the obtained results from the software module for the analytical calculation of motor parameters and operating characteristics for all six models of LSSPMM. According to Table 2 all motor designs show similar operating characteristics, i.e. efficiency in all models is relatively the same ranging from $94.9 \%$ to $95.2 \%$. Model V2 was not further analysed as it has the lowest efficiency $94.3 \%$ from all models and relatively low power factor. This application of the design V2 is highly dependent on available space in the rotor for placing the flux barriers and the magnets, i.e. it depends on the rotor slots shape and available remaining space for barriers and magnets. Models $\mathrm{BM}$ and $\mathrm{V} 1$ were also ruled out from further analysis due to lower efficiency and larger consumption of permanent magnet material than the other models. The further analysis proceeds with models V3, V4 and V5. Here should be stated that model V3 has the best performance characteristics from all models, i.e. the highest efficiency and the power factor combined with the smallest consumption of permanent magnet material and the largest overloading capability of the motor. As for the models, V4 and V5 have almost the same efficiency, power factor and consumption of permanent magnet material. All three models V3, V4 and V5 are candidates for further analysis, i.e. for deriving the numerical and transient models. The numerical models of V3, V4 and V5 are presented in Figure 6. All three models have points of the magnetic core with the high flux density, near the flux barriers. Therefore, the design of the motors can be further improved concerning the decreasing the flux density at critical areas of the magnetic core cross-section. Larger flux densities in stator yoke can be improved by increasing the stator outer diameter or decreasing the height of stator slots, subject to further analysis and optimisation. In this paper, the models of the line-start synchronous motor were derived based on the dimensions of the asynchronous motor, which was modelled on the base of the exact dimensions of the motor producer. This provides a base for comparison of the obtained results. The dynamic models allow obtaining the transient characteristics of speed, torque and current at motor acceleration up to the synchronous speed. The two different transient models were analysed: motor acceleration with the rated load and with step load, equal to the rated load, loaded to the motor shaft when acceleration had finished and the motor had reached the synchronous speed. All analysed motor models have sufficiently big starting torque so acceleration with rated load can be realised (Table 2). In Figures 7 and 8 after the acceleration is finished, the synchronous speed is reached. Motors are synchronised and continue with stable operation. The moment when the acceleration had finished and the synchronous speed was reached can be observed in Figures 9 and 11 as the torque and current dropped to the noload torque and no-load current. In Figures 9 and 11, also the moment when the motor is loaded with the step load can be observed from the increase of the torque and current, from the no-load value up to the rated torque and current. In Figure 9 and 11, the final values of torque and current are calculated for the last time interval for easier comparison with the analytical models. Figures 10 and 12 present the torque and the current when the motor is accelerated with rated load. After synchronous speed is reached, the torque and current drop to the rated torque and rated current. All motor models have approximately the same acceleration time. The comparison of the obtained results from the analytical models (Table 2) and the obtained results from the dynamic models is presented in Table 3 . The final values of speed, current and torque, in the last time interval, are calculated and they are presented in Figures 7-12.

Table 3. Comparison of analytical and dynamic models

\begin{tabular}{|c|c|c|c|c|c|c|}
\hline \multirow[t]{3}{*}{ Parameter } & \multicolumn{6}{|c|}{ Acceleration with rated load } \\
\hline & \multicolumn{3}{|c|}{ Analytical model } & \multicolumn{3}{|c|}{ Dynamic model } \\
\hline & V3 & V4 & V5 & V3 & V4 & V5 \\
\hline Rated current (A) & 3.6 & 3.6 & 3.6 & 3.6 & 4.1 & 4.2 \\
\hline Rated torque (Nm) & 14 & 14 & 14 & 14 & 14 & 14 \\
\hline \multirow[t]{2}{*}{ Speed (rpm) } & 1500 & 1500 & 1500 & 1500 & 1500 & 1500 \\
\hline & \multicolumn{6}{|c|}{ Step load } \\
\hline No-load current (A) & 2.6 & 2.6 & 2.6 & 2.8 & 3.4 & 3.5 \\
\hline Rated current $(\mathrm{A})$ & 3.6 & 3.6 & 3.6 & 3.6 & 4.1 & 4.2 \\
\hline Rated torque (Nm) & 14 & 14 & 14 & 14 & 14 & 14 \\
\hline Speed (rpm) & 1500 & 1500 & 1500 & 1500 & 1500 & 1500 \\
\hline
\end{tabular}


The presented results in Table 3 from both models (analytical and dynamic) are similar so that it can be stated that models are sufficiently accurate. All three models of LSSPMM have a good dynamic response at load change. They have been accelerated and synchronised without problems. The models are well designed concerning the squirrel cage winding (originally, the same winding from the asynchronous motor), the flux barriers and permanent magnet material inside them. However, the presented results are the starting results in the research obtained from simulation software. Construction of the prototypes and their measurements can validate the obtained theoretical results and prove the above-derived conclusions for the presented models of LSSPMM.

\section{Conclusion}

Finding the optimal motor design in terms of efficiency, power factor and material consumption can be a challenging task especially for the line-start synchronous motors where exist numerous different configurations of the rotor. This paper analyses six different configurations of the rotor of LSSPMM. The first or the basic configuration is derived from the asynchronous motor by adding flux barriers and permanent magnets. The windings, stator laminations, the motor outer dimensions and motor output power remain unchanged compared with the asynchronous motor. Five more variations of the rotor design of LSSPMM were derived by keeping the same constraints as in the BM and changing the shape and position of the flux barriers and the amount of the permanent magnet material needed for obtaining the same output power of the motor. All six models have almost the same efficiency; some bigger variations are observed in the value of the power factor and one model has bigger consumption of permanent magnet material. By analysing the overall performance of all models, it can be concluded that the fourth model or design V3 has the best efficiency and power factor along with the smallest consumption of permanent magnet material from all models. This model, as well as the fifth (V4) and the sixth (V5) model, has the best efficiency and power factor combined with the smallest consumption of permanent magnet material. These three models are further analysed for magnetic flux density distribution and the transient characteristics of speed, torque and current. All three models have points of high magnetic flux density near to the sharp ends of flux barriers. Further modification and improvement of the design of the motors should be considered. All three models have stable operation when they are accelerated with the rated load or when the step load is added to the motor shaft, after the acceleration has finished, and synchronous speed is reached. This is due to the sufficiently large starting torque and well-designed squirrel-cage winding that contributes to the asynchronous starting of the motor. From the aspect of the permanent magnet material, the motor is well designed in a way that synchronisation is achieved. The accuracy of the dynamic models and the obtained transient characteristics are verified by comparison with the obtained values of the current, torque and speed from the steady-state characteristics.

All six models have similar operating characteristics concerning the efficiency. One model has a bigger consumption of permanent magnet material for the same output power of the motor. Bigger variation of the value of the power factor among the models is observed. Although all six models of the motor can be equally used, when there are bigger demands in terms of the efficiency, power factor and cost of the material, the model V3 can be chosen as the most favourable option. A careful analysis of the motor design, especially of the rotor of line-start synchronous motor, can contribute to the improved energy efficiency along with cost savings for the material of the motor. Further research should be focused on finding an even more optimal design of this type of motor in terms of the improved efficiency and cost savings for the material consumption and thermal analysis and thermal modelling of the motor.

\section{References}

Ashkezari, J. D., Khajeroshanaee, H., Niasati, M. and Jafar Mojibian, M. (2017). Optimal design and operation analysis of permanent magnet-assisted synchronous reluctance motor. Turkish Journal of Electrical Engineering \& Computer Science, 25(3), pp. 1894-1907.
Bao, Y., Liu, L., Zhang, Y. and Feng, X. (2011). Performance investigation and comparison of line start-up permanent magnet synchronous motor with super premium efficiency. In: Proceedings of International Conference of Electrical Machines Systems. Beijing, 20-23 August 2011. 
Binkowski, T. (2016). Investigation of high speed motor drive operating in household appliances. Power Electronics and Drives, 1(36), No.2, pp. 41-53.

Dinh, B. M. (2017). Optimal rotor design of line-start permanent magnet synchronous motor by genetic algorithm. Advances in Science Technology and Engineering System, 2(3), pp. 1181-1187.

Els, J. P., Sorgdrager, A. and Wang, R. J. (2014). A study of rotor topologies of line start PM motors for cooling fan applications. In: Proceedings of $22^{\text {nd }}$ South African Universities Power Engineering Conference, Durban, January 2014.

Ghahfarokhi, M. M., Aliabad, A. D., Boroujeni, T. S., Amiri, K. and Faradonbeh, Z. V. (2020). Analytical modeling and optimization of line start LSPM synchronous motor. IET Electric Power Applications, 14(3), pp. 398-408.

Ghoroghchian, F., Aliabad, D. A. and Amiri, E. (2019). Design and analysis of consequentpole line start permanent magnet synchronous motor. IET Electric Power Applications, 14(4), pp. 678-684.

Gieras, F. J. (2019). Design of high-speed permanent magnet machines. Przegląd Elektrotechniczny, 95(12), pp. 1-8.

Gwoździewicz, M., and Zawilak, J. (2016). Single-phase line start permanent magnet synchronous motor with skewed rotor. Power Electronics and Drives, 1(36), No.2, pp. 187-194.

Hussein, I., Al-Hamouz, Z., Abido, A. M. and Milhem, A. (2018). On the mathematical modeling of line-start permanent magnet synchronous motor under static eccentricity. Energies, 11(1), pp. 1-17.

Kim, X., Park, Y., Liu, H-C., Han, P-W. and Lee, J. (2020). Study on line-start permanent magnet assistance synchronous reluctance motor for improving efficiency and power factor. Energies, 13(2), pp. 1-15.

Knypiński, Ł. (2017). Optimal design of the rotor geometry of line-start permanent magnet synchronous motor using the bat algorithm. Open Physics. 15(1), pp. 965-970.

Knypiński, Ł. and Krupiński, J. (2020). Application of the permanent magnet synchronous motors for tower cranes. Przegląd Elektrotechniczny, 96(1), pp. 27-30.

Končar, MES d.d. (2014). Three-phase squirrel cage, [online]. Available at: http://www.koncar- mes.hr/wp-content/uploads/katalog/katalog_ elektromotori_2014_trofazni-kavezni-asinkronielektromotori.pdf [Accessed 9 Apr 2020].

Kumar, D. S., Manamalli, D. (2013). Development of induction motor efficiency model and improving at low load condition using controllers. International Journal of Computer Applications, 75(16), pp. 1-8.

Mutluer, M. and Bilgin, O. (2016). An intelligent design optimization of a permanent magnet synchronous motor by artificial bee colony algorithm. Turkish Journal of Electrical Engineering \& Computer Science, 24(3), pp. 1826-1837.

Sarac, V., Minovski, D., and Janiga, P. (2017). Numerical and analytical model of induction motor for computer-aided design. International Journal of Information Technology and Security, 9(2), pp. 65-82.

Sekerák, P., Hrabovcová, V., Pyrhönen, J., Kalamen, L., Rafajdus, P. and Onufer, M. (2012). Ferrites and different winding types in permanent magnet synchronous motor. Journal of Electrical Engineering, 63(3), pp. 162-170.

Stoia, D., Cernat, M., Jimoh, A.A. and Nicolae, V.D. (2009). Analytical design and analysis of linestart permanent magnet synchronous motor. In: Proceedings of IEEE AFRICON. Nairobi, 23-25 September 2009.

Tian, M., Wang, X. and Li, G. (2016). Line-start permanent magnet synchronous motor starting capability improvement using pole-changing method. In: Proceedings of IEEE 11th Conference on Industrial Electronics and Applications. Hefei, 5-7 June 2016.

Trifa, R., Martis, C., Biro, K. and Gazdac, A. M. (2012). Design and analysis of a permanent magnet synchronous machine for automotive electromechanical braking system. Przegląd Elektrotechniczny, 88(7b), pp. 141-144.

Xu, X. (2013). Performance of line-start permanent magnet synchronous motor with novel rotor structure. International Journal of Digital Content Technology and its Applications, 7(6), pp. 1217-1225.

Zawilak, T. (2013). Utilizing the deep bar effect in direct on line start of permanent magnet machines. Przegląd Elektrotechniczny, 89(2b), pp. 177-179.

Zöhra, B., Akar, M. and Eker, M. (2019). Design of a novel line start synchronous motor rotor. Electronics, 25(8), pp.1-18. 